Original Article

\title{
Pediatric Head Injury: A Study of 120 Cases
}

\author{
Muhammad Asif, Waqar Aziz Rehman, Sumaira Serwar, Hamza Younas, Fatima Younas \\ Sahiwal Medical College/DHQ Teaching Hospital, Sahiwal - Pakistan
}

\begin{abstract}
Objectives: Head injury in the pediatric age group is a significant worldwide cause of death and morbidity. Falls are the most common cause of head injury followed by road traffic accidents (RTAs) in such patients. This study aimed to evaluate incidence, mode, and severity of injury, treatment options and to determine the outcome in pediatric age group patients with head injury.

Patients \& Methods: 120 pediatric patients with a head injury, with ages up to 15 years or less, were included. Detailed history, general and neurological examination including GCS were noted. The CT scans were conducted and the patients managed as per said protocol. Various surgical procedures were performed including craniotomies and evacuation of hematoma, the elevation of depressed fractures and repair of the dura, decompression craniotomies, and evacuation of Subdural collections and contusions.
\end{abstract}

Results: $60.1 \%$ of patients were boys and $39.16 \%$ were girls. In the majority (63\%) of the children, the 'fall' was reported. The majority of children (68.3\%) in our study had a mild head injury with GCS $13-15.35 .83 \%$ patients had normal CT scans, and $23.33 \%$ had isolated skull fractures. $68.75 \%$ patients were with a severe head injury and had a poor outcome. A poor outcome was noted in patients having brain edema, subdural hematoma, and brain contusions.

Conclusion: Head injury in the pediatric age group still continues to be a significant cause of mortality and morbidity. The outcome is directly being related to the severity of injury i.e., GCS. Falls and RTAs are the most common causes and preventive measures in different forms need to be addressed.

Keywords: Head Injury, Road Traffic Accidents, Glasgow Coma Scale, Concussion Injuries.

\section{Corresponding Author: Muhammad Asif}

Sahiwal Medical College Sahiwal/DHQ Hospital, Sahiwal Pakistan

Email: drasif2003@gmail.com

Date of Submission: 22-4-2021

Date of Revision: 23-5-2021

Date of Online Publishing: 13-6-2021

Date of Print: 30-6-2021

DOI: $10.36552 /$ pjns.v25i2.557

\section{INTRODUCTION}

Head injury has become a major cause of disability and death in pediatrics group and is ubiquitous. It has got the attention of neurosurgeons because this age group population has to spend long years of life ahead. Head injury and its sequel have a bearing on the family, society, and the economics of a country. ${ }^{1}$ Review of worldwide incidence rates revealed the variations by countries with a range from $47-280$ 


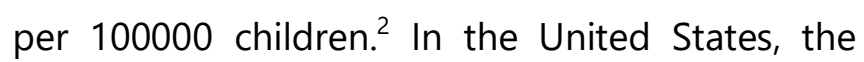
annual admissions to emergencies reach a staggering half a million patients. ${ }^{3}$ The most common cause of death in children in the United States has been reported to be head injury and it approximates about $70-80 \% .{ }^{4,5}$ Although the boys do suffer more head injury than girls, the incidence of mild head injury is more in girls. ${ }^{6}$ Among the High school age group girls have high rates of concussion, compared to boys. ${ }^{7}$

Falls are on the top while discussing the mode of injury followed by road traffic accidents. ${ }^{8}$ Child abuse is also an important reason for head injury especially in infants and young children as they are more vulnerable and dependent on adults. ${ }^{9}$ Head injury may be classified as mild (GCS 13 15), moderate (GCS $9-12$ ), or severe (GCS 3 8). ${ }^{10} \mathrm{CT}$ scan brain is the most effective and definitive tool to know the nature and severity of the injury which helps in decision making with regards to final treatment. ${ }^{11,12,13} \mathrm{~A}$ wide range of factors can be considered while making decisions and assessing prognosis. Practically only a few features were found to have most of the prognostic information. ${ }^{14,15,16}$ These include age, GCS, and CT findings indicating severity and nature of the head injury. ${ }^{17}$ In spite of the fact that the majority of the children do get a mild head injury, only a few percentages have complications and associated morbidity and mortality. ${ }^{18,19}$ It is well observed that such children may develop cognitive and behavioral problems after such concussions and posttraumatic stress disorder (PTSD). ${ }^{20}$ Severe head injuries are relatively less common catering for $10 \%$ of head injury patients. ${ }^{21}$ Sharples et $\mathrm{al}^{22}$ had observed that $30 \%$ of deaths could be avoided. Quick and accurate diagnosis and provision of ICU care is of vital importance for decreasing the mortality rates. Secondary injuries to the brain, hypoxia, and hypotension, may develop early and play role in enhancing the effect of the primary injury. These must be managed at the earliest and best possible levels. ${ }^{23}$ The current study evaluated the incidence, mode, and severity of the injury, treatment options and to determine the outcome in pediatric age group patients with a head injury.

\section{MATERIALS AND METHODS}

\section{Study Design \& Setting}

A cross-sectional study was conducted on 120 pediatric patients with age up to 15 years in the Department of Neurosurgery in DHQ Teaching Hospital/Sahiwal Medical College Sahiwal. The study was conducted for a period of one year from 1st July 2018 to 30th of June 2019.

\section{Inclusion Criteria}

Those patients were admitted who reported the head injury.

\section{Exclusion Criteria}

Multiple trauma patients.

\section{Data Collection}

Detailed history including age, sex, mode of injury was taken. General physical and systemic examinations including a central nervous system were done and Glasgow Coma Scores (GCS) were noted in every patient. Patients were grouped as mild, moderate, and severe head injuries on the basis of GCS. Patients were resuscitated and once vitally stable, the CT Scan brain was done and $\mathrm{CT}$ findings were noted and treatments were planned i.e. conservative/surgery. In the end, the ultimate outcome was assessed and grouped into good (normal or moderate disability) and poor (severe disability, vegetative, and death) following the Glasgow outcome scale.

\section{RESULTS}

\section{Age Distribution}

Out of 120 patients, 52 (43.3\%) were of 5 years of 
age, whereas, there were $68(56.6 \%)$ patients who were between $6-15$ years (Table 1).

\section{Gender Distribution}

73 (60.1\%) were boys and 47 (39.16\%) were girls, with male to female ratio of almost 3:2 (Table 1).

Table 1: Distribution of 120 Children with Regard to Age, Sex \& Mode of Injury.

\begin{tabular}{lcc} 
Parameter & Number & Percentage \\
Age Group & & \\
$\leq 5$ (years) & 52 & $43.33 \%$ \\
$6-15$ (years) & 68 & $56.66 \%$ \\
Sex & & \\
Male & 73 & $60.83 \%$ \\
Female & 47 & $39.16 \%$ \\
Mode of Injury & & \\
Falls & 76 & $63.33 \%$ \\
Road Traffic Accidents & 30 & $25 \%$ \\
$\begin{array}{l}\text { Others: } \\
\text { Sport injury \& }\end{array}$ & & $11.66 \%$ \\
Fire Area Injury & 14 & \\
\hline
\end{tabular}

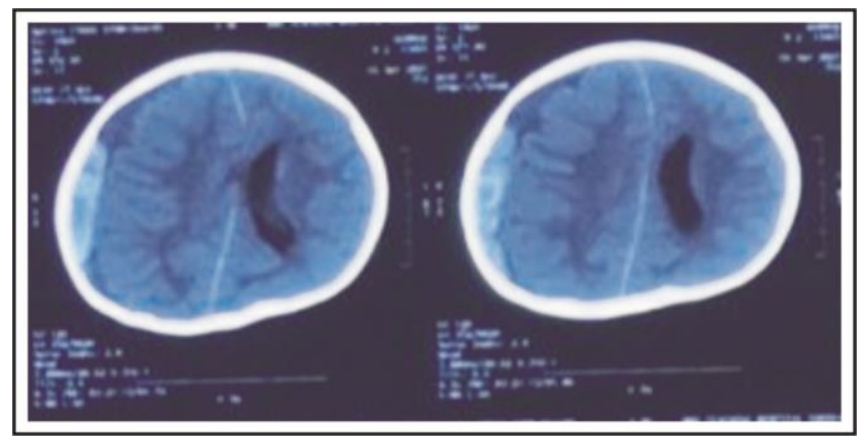

Figure 1: Subdural hematoma with mass effect in 5-year-old child.

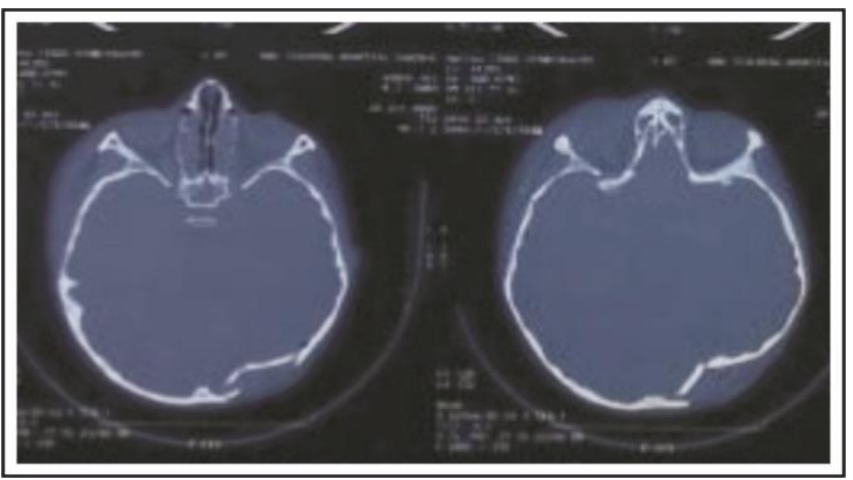

Figure 2: Depressed fracture 3-year-old child.

\section{Mode of Injury}

In the majority (63\%) of the children, the 'fall' was reported, the preschool children followed by road traffic accidents was $25 \%$ and injuries from other modes (sports, arum injury, or collided with some hard object) were $11.66 \%$ (Table 1).

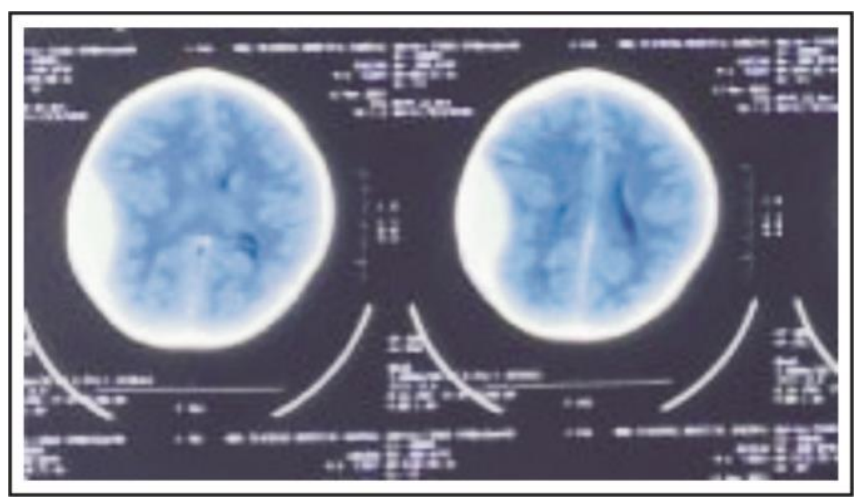

Figure 3: Extradural hematoma in 6-year-old child.

\section{GCS Scores and Injury Levels}

The majority of children (68.3\%) in our study had a mild head injury with GCS $13-15$, followed by moderate head injury (18.3\%) with GCS 9 - 12, and severe head injury (13.3\%) with GCS $3-8$ (Table 2).

\section{Findings of CT-Scans}

Forty-three (35.83\%) patients had normal CT scan, 28 (23.33\%) had isolated skull fractures. Depressed fractures along with underlying brain contusions were noted in 12 (10\%) children. Extra dural hematomas were seen in $9(7.5 \%)$ children. Six (5\%) patients had Subdural hematoma with underlying brain contusions and 8 (6.66\%) children had brain edema.

Subdural hematoma mentioned in Figure 1, depressed fracture in Figure 2, and extradural hematoma in Figure $\mathbf{3}$ are the CT findings of our study.

\section{Outcome from CT Scans}

The ultimate outcome was assessed with the 
Glasgow outcome scale. 11 (68.75\%) patients with severe head injury had poor outcomes, followed by $6(27.27 \%)$ patients with a moderate head injury. 2 (2.43\%) children were with a mild head injury and had poor outcome (Table 2).

Table 2: Relationship of Glasgow Coma Score (GCS) with Outcome (Glasgow outcome scale).

\begin{tabular}{|ccccc|} 
GCS & $\begin{array}{c}\text { Good } \\
\text { Outcome }\end{array}$ & $\begin{array}{c}\text { Poor } \\
\text { Outcome }\end{array}$ & Total \\
$13-15$ & 80 & $2(2.43 \%)$ & $82(68.33 \%)$ \\
$9-12$ & 16 & $6(27.27 \%)$ & $22(18.33 \%)$ \\
$\leq 8$ & $5(31.25 \%)$ & $11(68.75 \%)$ & $16(13.33 \%)$ \\
\hline
\end{tabular}

As far as CT scan findings and outcomes are concerned, a poor outcome was noted in patients having brain edema, subdural hematoma, and brain contusions. Various surgical procedures were performed including craniotomies and evacuation of hematoma in 9 (7.5\%) patients, the elevation of depressed fractures, and repair of dura in 22 (10\%) patients. Six (5\%) patients underwent decompression craniotomies, evacuation of Subdural collections, and contusions. Poor outcomes were in those patients who presented late due to delayed referred.

\section{DISCUSSION}

The functional impact of head injury in a pediatric age group may be different as compared to adults. The Neurosurgical changes may not be apparent at the time of impact as the pediatric brain is in the process of development. The children head injury is supposed to be a slowly progressive disease rather than one-time event because the symptoms may change and unfold over time. ${ }^{24}$ Head injured in children are commonly affected by post-concussion syndrome and cognitive impairment. A piece of quick advice and prompt treatment can allay worse outcomes. In the developed world, the availability of specialized intensive care units and by a multidisciplinary approach, the outcome of head injury patients have improved dramatically, but it is still a major challenge for the neurosurgeons in developing nations like ours. ${ }^{5}$

Despite the development in the field of medicine in general and neurosurgery field, the significant morbidity and mortality persist in pediatric head injury patients. ${ }^{23}$ It has been observed that the outcome of children is better than the adults. However, some studies claim that children below 5 years show a poor outcome. ${ }^{27-28}$ Garg et al $^{23}$ had observed that the patient's age bears a significant impact on the outcome. They reported a mortality rate of $57 \%$ in children below one year as compared to $12 \%$ in children older than 5 years. In this study, 69\% of patients were boys which is consistent with findings. Rivera et $\mathrm{al}^{29}$ had reported that the incidence of head injury in boys, doubles that of girls. Although this gender difference is important in the rate of head injury, it does not have adverse effects on ultimate outcome.

In our study, the commonest modes of head injury were 'falls' (63.33\%), followed by road traffic accidents (25\%), and $11.66 \%$ had other modes of injuries i.e., sports injury, firearm injury, and injury by something hit to head. In a study by Abrar, ${ }^{25}$ the most common modes of head injury were falls (57\%) followed by RTAs (33.8\%) and other modes were in $6.7 \%$ only. Many authors had mentioned that GCS is an excellent predictor of outcome/mortality. ${ }^{30,31}$ Abrar $^{25}$ mentioned their patients with GCS 13 - 15 (57.3\%) who had poor outcome (2.6\%), followed by GCS 9 - 12 (29.8\%) with poor outcome in $2.52 \%$ patients. In patients with GCS 8 or below (13\%), a poor outcome was observed in $65.4 \%$ patients. A study by Astrand et $\mathrm{al}^{32}$ had shown a poor outcome of $0 \%$ in patients presenting with GCS of 13-15, in patients with GCS $9-12$ as $6.2 \%$ and in patients with GCS 8 and below had 22\% poor outcomes. In this study, the outcome was poor in severe head injury (GCS 8 or lower) and was noted in 11 (68.75\%) patients, followed by moderate head 
injury (GCS $9-12$ ), the poor outcome was noted in $6(27.27 \%)$ patients. If the injury was mild (GCS 13 - 15), then there was a poor outcome in 2 (2.43\%) patients. In our study, we have noticed the presenting GCS as a strong determinant of clinical outcome. Ong et $\mathrm{al}^{33}$ and Aldrich et $\mathrm{al}^{34}$ have reported that the GCS as an unreliable predictor of outcome in the absence of conditions like hypoxia or ischemia. Due to poor resuscitation at the peripheral hospitals and late referral to Specialized Neurosurgical Units, patients do suffer from hypoxia leading to poor outcomes in such head-injured patients. A review of different studies has shown that falls i.e., from rooftop, stairs, windows, walls, and trees, are the commonest modes of head injury in children. It has been stressed to follow the preventive measures to avoid such injuries i.e., safer designs of houses, roof walls should have boundary walls and stairs should be well guarded. Environmental preventive measures - abide by traffic rules, use of seat belts, use of helmets, traffic calming measures, road safety measures, must be sustained to avoid the RTAs and head injuries.

\section{CONCLUSION}

From this study we concluded that:

1. Falls are the commonest modes of head injury followed by road traffic accidents, preventive measures related to the environment must be strictly observed to reduce the incidence of pediatric head injuries.

2. Primary resuscitation measures in peripheral hospitals must be followed to avoid hypoxia and secondary brain injury and early referral to Specialized Neurosurgical Units must be encouraged.

\section{REFERENCES}

1. Naveed Ashraf et al. Epidemiology of Pediatric Cranio-Cerebral Trauma. Journal of Neurological Surgery, 1998; 1 (1): 16-20.
2. Devam MC, Mummadeddy N, Wellons JC, Bonfjeld CM. Epidemiology of global pediatric traumatic brain injury: Qualitative review. World Neurosurgery, 2016; 91: 497-509.

3. Faul $M, X u L$, Wald MM, Coronado VG. Traumatic brain injury in United States: Emergency department visits, hospitalizations and deaths 2002-2006. Atlanta, GA: Centers for disease control and prevention, National Center for Injury Prevention and Control, 2010. ID5571

4. Langlois JA, Sattin RW. Traumatic brain injury in the United States: Research and programs of the Centers for Disease Control and Prevention (CDC). J Head Trauma Rehabil. 2005; 20: 187-8.

5. Lam WH, MacKersie A. Paediatric head injury: Incidence, aetiology and management. Paediatr Anaesth. 1999; 9: 377-85.

6. Lincoln $A E$, Caswell SV, Almquist JL, Dunn RE, Norris JB, Hinton RY. Trends in concussion incidence in high school sports: A prospective 11year study. American Journal of Sports Medicine, 2011; 39: 958-963.

7. Covassin T, Moran R, Elbin RJ. Sex differences in reported concussion injury rates and time loss from participation: An update of the National Collegiate Athletic Association Injury Surveillance Program from 2004-2005 through 2008-2009. Journal of Athletic Training, 2016; 51: 189-194.

8. Adirim TA, Wright $\mathrm{J}$, Lee $\mathrm{E}$, Lomax $T A$, Chamberlain JM. Injury surveillance in a pediatric emergency department Am J Emerg Med. 1999; 17: 499-503.

9. Kumar R, Mahapatra AK. The changing "epidemiology" of pediatric head injury and its impact on the daily clinical practice. Childs Nerv Syst. 2009; 25: 813-23.

10. Teasdale G, Jennett B. Assessment of coma and impaired consciousness. A practical scale. Lancet, 1974; 2: 81-4.

11. Trenchs V, Curcoy Al, Castillo M, Badosa J, Luaces $C$, Pou J, et al. Minor head trauma and linear skull fracture in infants: Cranial ultrasound or computed tomography? Eur J Emerg Med. 2009; 16: 150-2.

12. Ringl $H$, Schernthaner $R$, Philipp MO, MetzSchimmerl S, Czerny C, Weber $M$, et al. Threedimensional fracture visualisation of multidetector CT of the skull base in trauma patients: Comparison of three reconstruction algorithms. 
Eur Radiol. 2009; 19: 2416-24.

13. Gennarelli TA, Spielman GM, Langfitt TW, Gildenberg $P L$, Harrington $T$, Jane $J A$, et al. Influence of the type of intracranial lesion on outcome from severe head injury. J Neurosurg. 1982; 56: 26-32.

14. Braakman R, Gelpke GJ, Habbema JD, Maas Al, Minderhoud JM. Systematic selection of prognostic features in patients with severe head injury. Neurosurgery, 1980; 6: 362-70.

15. Jennett B, Teasdale G, Braakman R, Minderhoud J, Heiden J, Kurze $T$, et al. Prognosis of patients with severe head injury. Neurosurgery, 1979; 4: 283-9.

16. Stablein DM, Miller JD, Choi SC. Statistical methods for determining prognosis in severe head injury. Neurosurgery, 1980; 6: 243-8.

17. Chesnut RM, Ghajar J, Maas AR. Guidelines for the Management and prognosis of severe traumatic brain injury part II: Early indicators of prognosis in severe traumatic brain injury. J Neurotrauma, 2000; 17: 556-627.

18. Trefan L et al. Epidemiology of Children with Head Injury: a national overview. Arch Dis Child, 2016; 101: 527-532.

19. Kraus JF, Rock A, Hemyari P. Brain injuries among infants, children, adolescents, and young adults. Arch Pediatr Adolescents and Young Adults. Arch Pediatr Adolesc Med. 1990; 144: 684-91.

20. Anderson T, Heitger M, Macleod AD. Concussion and mild head injury. Pract Neurol. 2006; 6: 34257.

21. Meyer PG. Paediatric trauma and resuscitation. Curr Opin Anaesthesiol. 1998; 11: 285-8.

22. Sharples PM, Storey A, Aynsley-Green A, Eyre JA. Avoidable factors contributing to death of children with head injury. BMJ. 1990; 300: 87-91.

23. Garg K, Sharma R, Gupta D, Sinha $S$, Satyarthee GD, Agarwal D, Kale SS, Sharma BS, Mahapatra AK. Outcome predictors in pediatric head trauma: A study of clinicoradiological factors. Journal of Pediatric Neurosciences, 2017 Apr; 12 (2): 149.

24. DePompei, R., \& Tyler, J. S. (in press). Children and adolescents: Practical strategies for school participation and transition. In M. J. Ashley (Ed.), Traumatic brain injury: Rehabilitation, treatment, and case management. Boca Raton, FL: CRC Press.
25. Wani AA, Sarmast $A H$, Ahangar $M$, Malik NK, Chhibber SS, Arif SH, Ramzan AU, Dar BA, Ali Z. Pediatric head injury: a study of 403 cases in a tertiary care hospital in a developing country. Journal of Pediatric Neurosciences, 2017; 12 (4): 332.

26. Tepas JJ, 3rd, DiScala C, Ramenofsky ML, Barlow B. Mortality and head injury: The pediatric perspective. J Pediatr Surg. 1990; 25: 92-5.

27. Humphreys RP, Jaimovich $R$, Hendrick EB. Concepts in Pediatric Neurosurgery. Severe Head Injury in Children, 1983; Vol. 3: pp. 191-201. Basel, Switzerland: Karger.

28. Lobato RD, Cordobes F, Rivas JJ, de la Fuente $M$, Montero A, Barcena A, et al. Outcome from severe head injury related to the type of intracranial lesion. A computerized tomography study. J Neurosurg. 1983; 59: 762-74.

29. Rivara FP, Bergman AB, LoGerfo JP, Weiss NS. Epidemiology of childhood injuries. II. Sex differences in injury rates. Am J Dis Child. 1982; 136: 502-6.

30. Bruce DA, Raphaely RC, Goldberg Al, Zimmerman RA, Bilaniuk LT, Schut L, et al. Pathophysiology, treatment and outcome following severe head injury in children. Childs Brain, 1979; 5: 174-91.

31. Levin HS, Aldrich EF, Saydjari C, Eisenberg HM, Foulkes MA, Bellefleur $M$, et al. Severe head injury in children: Experience of the Traumatic Coma Data Bank. Neurosurgery, 1992; 31: 435-43.

32. Astrand R, Undén J, Hesselgard K, Reinstrup P, Romner B. Clinical factors associated with intracranial complications after pediatric traumatic head injury: An observational study of children submitted to a neurosurgical referral unit. Pediatr Neurosurg. 2010; 46: 101-9.

33. Ong L, Selladurai BM, Dhillon MK, Atan M, Lye MS. The prognostic value of the Glasgow coma scale, hypoxia and computerised tomography in outcome prediction of pediatric head injury. Pediatr Neurosurg. 1996; 24: 285-91.

34. Aldrich EF, Eisenberg HM, Saydjari $C$, Luerssen TG, Foulkes MA, Jane JA, et al. Diffuse brain swelling in severely head-injured children. A report from the $\mathrm{NIH}$ traumatic coma data bank. J Neurosurg. 1992; 76: 450-4. 


\section{Additional Information}

Disclosures: Authors report no conflict of interest.

Ethical Review Board Approval: The study was conformed to the ethical review board requirements.

Human Subjects: Consent was obtained by all patients/participants in this study.

Conflicts of Interest:

In compliance with the ICMJE uniform disclosure form, all authors declare the following:

Financial Relationships: All authors have declared that they have no financial relationships at present or within the previous three years with any organizations that might have an interest in the submitted work.

Other Relationships: All authors have declared that there are no other relationships or activities that could appear to have influenced the submitted work.

\section{AUTHORS CONTRIBUTIONS}

\begin{tabular}{|l|l|l|}
\hline Sr.\# & Author's Full Name & Intellectual Contribution to Paper in Terms of: \\
\hline 1. & Muhammad Asif & Study design and methodology. \\
\hline 2. & Muhammad Asif & Paper writing, referencing, data calculations and \\
\hline 3. & Waqar Aziz Rehman & Data collection and calculations. \\
\hline 4. & Sumaira Serwar & Analysis of data and interpretation of results etc. \\
\hline 5. & Muhammad Asif & Literature review and manuscript writing. \\
\hline 6. & Sumaira Serwar & Analysis of data and quality insurer. \\
\hline
\end{tabular}

